\title{
The Social and Ecological Trajectory of Prehistoric Cambodian Earthworks
}

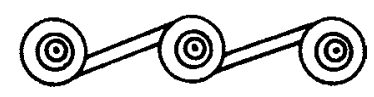

\author{
MICHAEL DEGA AND D. KYLE LATINIS
}

\section{INTRODUCTION}

Archaeological research on prehistoric Circular earthworks (banteay kou) located in the basaltic hill region of eastern Cambodia and southwestern Viet Nam has traditionally focused on site geographic location, site morphology, and artifacts recovered from the sites (Fig. 1). From the time of B. P. Groslier's detailed account of the sites in the 1960s, researchers and archaeologists have utilized these more traditional archaeological approaches (Albrecht et al. 1999; Dega 1999, 2002; Dega et al. 1997; Haidle 2002; Kojo and Pheng 1997; Nop et al. 1996; Sophady n.d.). This is reasonable given the enigmatic nature of the sites and the desire to understand them in terms of historic timelines, spatial arrangements, and technological, stylistic, and functional developments. These projects have led to intriguing conclusions regarding earthwork occupants, dates, and material culture that generally concur with the original Groslier (1966) thesis that the sites represent a unique social grouping or culture (Dega 2002).

More recently, forays into understanding additional aspects of the sites through soil science, palynology, and landscape traits have broadened the discussion of this archaeological period and site grouping (Albrecht 1999; Dega 2002). Recent ceramic compositional analyses using energy dispersive x-ray fluorescence (EDXRF) (Latinis and Dega 2009) clearly differentiate the banteay kou pottery tradition from the floodplain pottery of pre-Funan and Funan period settlements, whose beginnings partially overlap the terminal dates for banteay kou occupation and use (Latinis and Dega 2009).

Starting from this normative archaeology foundation, this article moves discussion of the banteay kou phenomenon in the direction of landscape archaeology cum historical ecology to explain more elements of this unique social system. The earthwork grouping may be better understood in terms of cultural and environmental relationships through time and space. ${ }^{1}$ Viewed through the lenses of archaeology and historical ecology, we examine the sites using an original model that accommodates: 1) initial site formation; 2) continued construction, occupation, and use; and 3) possible reasons for site-use decline or abandonment and the cessation of earthwork construc-

Michael Dega is part of the Naga Research Group in Honolulu, Hawai'i. D. Kyle Latinis was previously Director of the Institute for Research and Advanced Studies and Dean of Graduate Studies at the University of Cambodia. He is now Director of the Social Science Directorate, Human Terrain System, United States Army. 


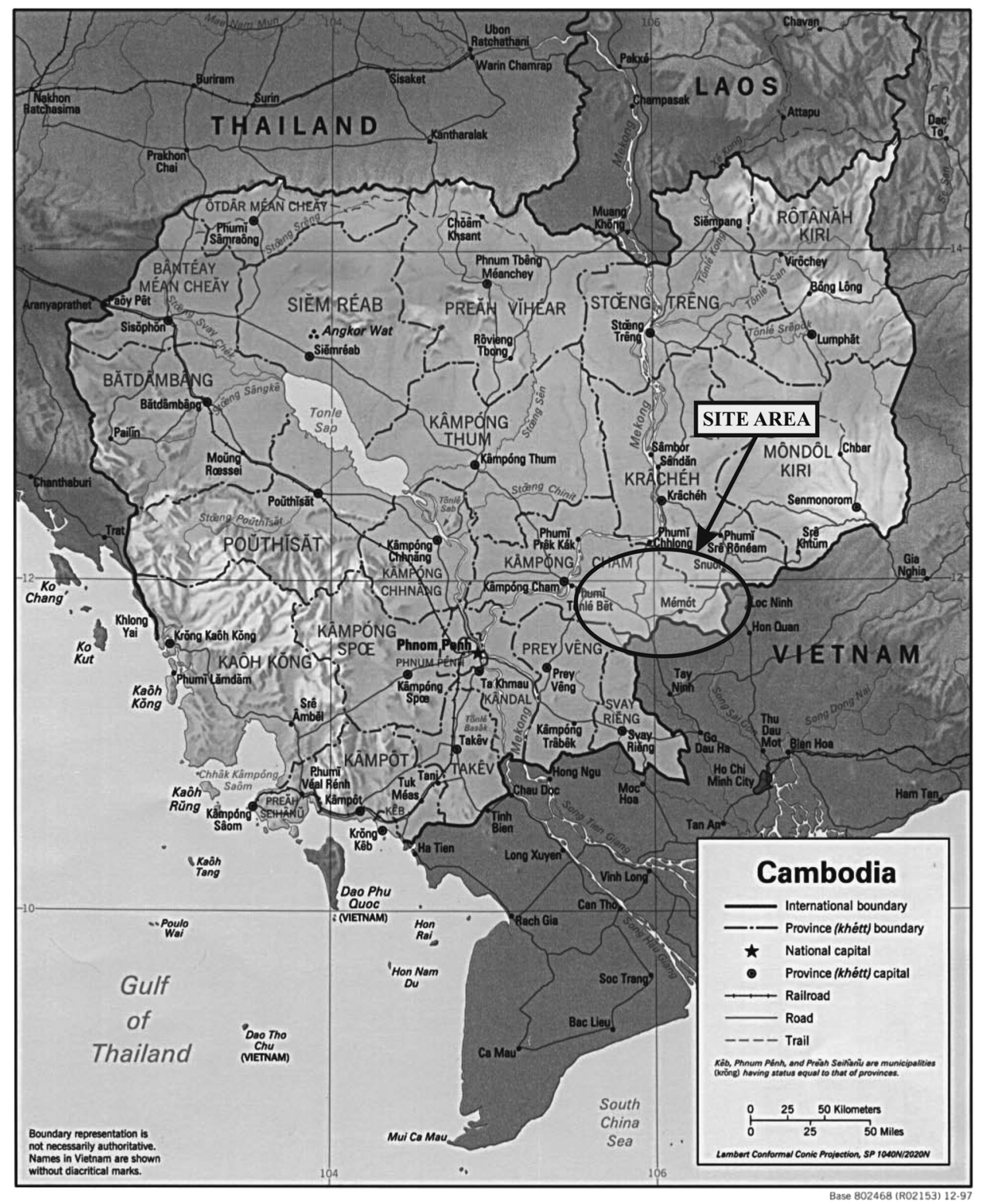

Fig. 1. Map of Cambodia circular earthwork regional location, 1977 (Base 802468, Perry-Castaneda Library Map Collection, University of Texas Libraries, Austin).

tion at c. 500-0 B.C. Sustained earthwork settlement for over 2000 years is explained in terms of an ecological relationship in which site inhabitants only minimally altered the macroecosystem they occupied.

We suggest that a marriage between landscape archaeology/historic ecology and normative archaeology immediately broadens our understanding of earthworks and all archaeological sites through time and space. Interwoven through the text are two 
overall themes: first, how this Memotian society impacted and interacted with the environment (ecology) and, second, considering the principles of shared cultural traits, how the culture survived through time without having to radically alter its land use and settlement practices.

\section{CIRCULAR EARTHWORKS: ARCHAEOLOGICAL FOUNDATION}

A series of $33+$ circular earthworks was constructed in a red-soil hill region (terra rouge plateau) of eastern Cambodia / western Viet Nam between 2300 and 300 B.C. (Dega 2002; see Fig. 1). The sites are located on hilltops overlooking a red upland landscape and nearby floodplains (Fig. 2). They were constructed at a transitional facies between lowland floodplains and upper terraces, the latter of which proceed into the central Vietnamese highlands and the uplands of Northeast Cambodia. Between the westernmost Cambodian earthwork-Krek no. 15-the easternmost earthwork near Phoum Hong Slats, direct geographical distance measures approximately $55 \mathrm{~km}$ on an east-west axis. The largest separation of earthwork sites on a north-south axis is approximately $22 \mathrm{~km}$. When incorporating the earthwork sites in Viet Nam, the eastwest axis extends to $85 \mathrm{~km}$ while the north-south axis is extended to approximately $35 \mathrm{~km}$. The total known area of the earthwork domain is thus roughly $2975 \mathrm{~km}^{2}$, revealing a fairly low density of sites $(n=33) .^{2}$

The sites occur on stable surfaces and average just less than 5 ha in size. Except for restricted passageways, they are enclosed by a large, circular, earthen wall. Individual circular settlements consist of a concentric earthen embankment surrounding an inner concentric depression and interior platform (Figs. 3-5). No one site dominates the grouping in terms of size or structural elaboration.

Absolute dating revealed that site construction and occupation occurred between about 2300 and 300 B.C. Some contemporaneity in site occupation may be suggested between the sites, the exception being no overlap in occupation between the oldest site in the east (Phoum Trameng) and the youngest site in the west (Chi Peang). The small sample of dates revealed that sites were progressively younger from east to west. An occurrence seriation of decorative ceramic traits supports this interpretation (Dega 2002).

The earthwork lithic toolkit was primarily oriented toward agricultural and horticultural use, particularly in or near forested areas. A majority of the tools are characteristic of clearance, cutting, chopping, and various kinds of woodworking. In ecological terms, the industry focused on persistence and predictability. Axes and adzes predominate. Axes, which are the most abundant, are generally used for chopping, cutting, and splitting relatively large pieces of wood from medium and large trees. They are also used for horticultural/agricultural plot clearance, chopping firewood, and construction wood extraction and processing. Adzes can be used for scrub and secondary growth clearance and ring barking as well, but are often more related to woodworking (i.e., wood crafting). Stone picks, drills, and files, among other tools, are also used for woodworking. These functions may indicate that a large portion of the toolkit was likely organic, that is wooden or "lignic" (W. Solheim, pers. comm., May 1995, University of Hawai'i).

The ceramic assemblage was primarily utilitarian, and reflected domestic use. Adequate clays are locally available to produce open-fired earthenware ceramic items. Based on the presence of clay materials in the earthwork region, potential tempering 


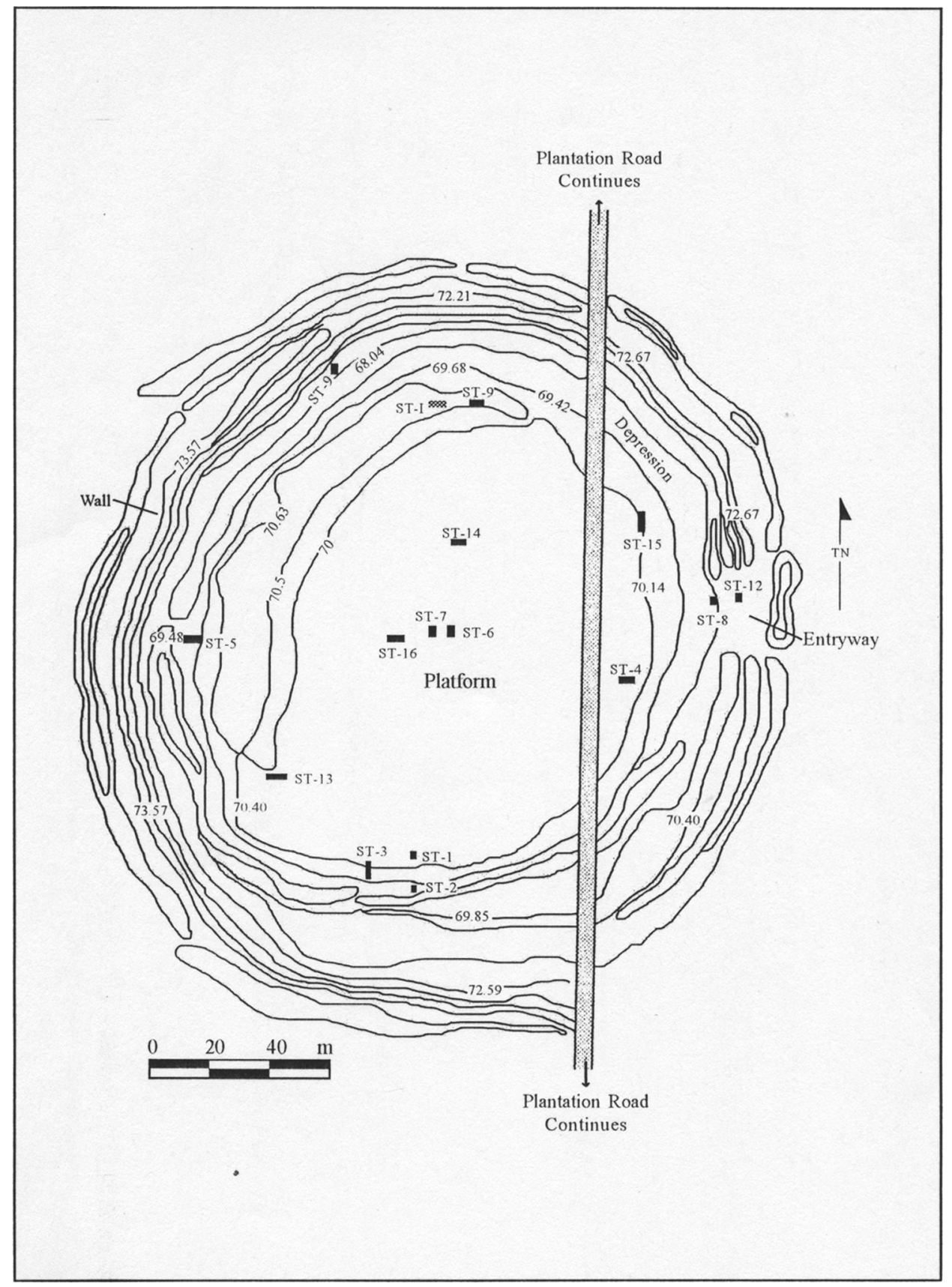

Fig. 2. Plan view map of circular earthwork (ST represents excavated stratigraphic trenches). 


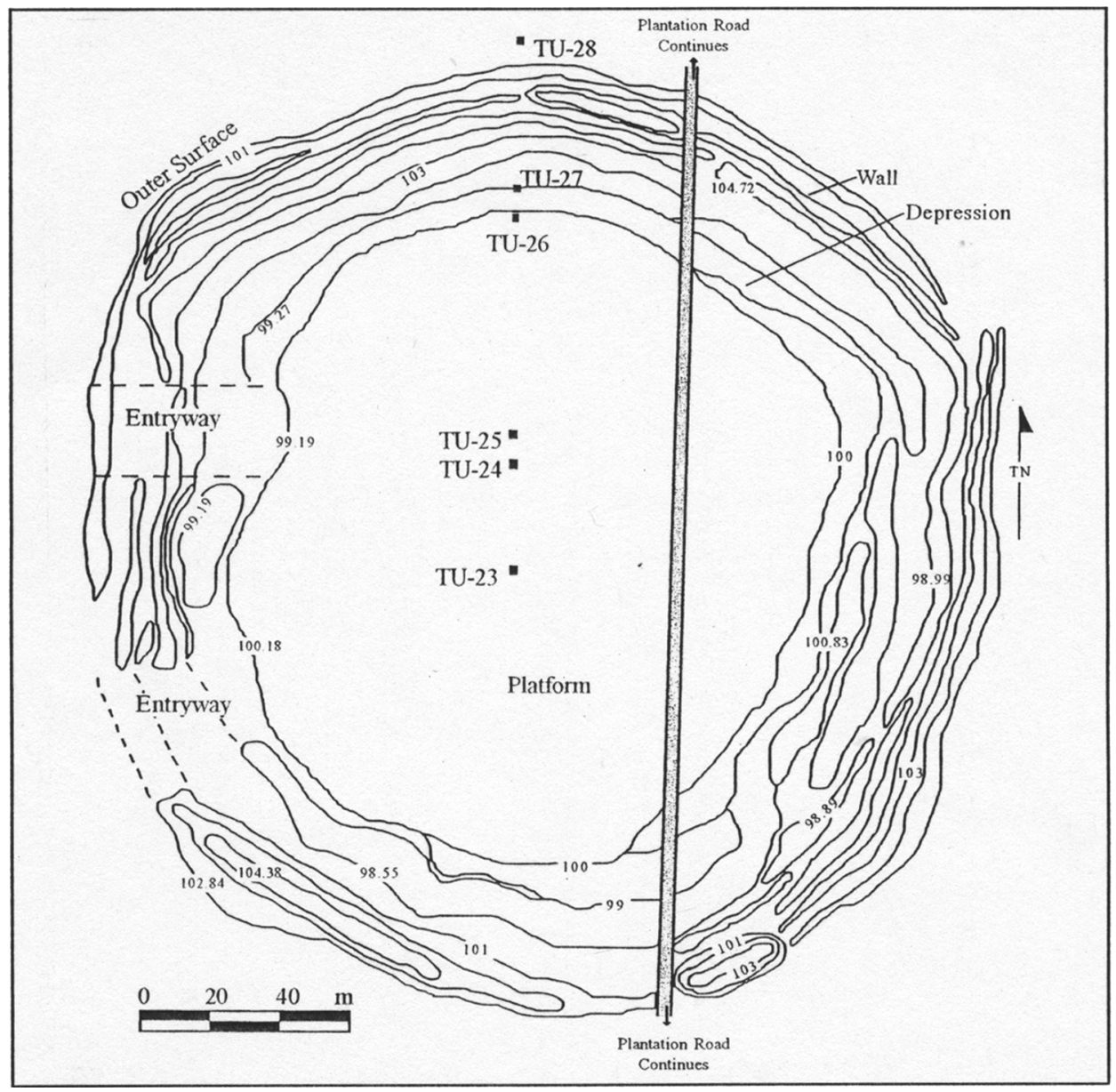

Fig. 3. Plan view map of circular earthwork (TU represents excavated test units).

agents (e.g., laterite), and thousands of recovered wasters, it is reasonable to assume that earthwork inhabitants produced ceramics. In addition, kaolinitic clays are prevalent across the basaltic plateau region. Based on EDXRF analyses that closely match soil samples with pottery matrices, we draw several conclusions: earthwork pottery consists of a uniquely similar internal composition that is distinct from early external floodplain pottery; local soils were used for pottery manufacture; and there was no monopoly on pottery production, as earthwork pottery was evenly distributed among the sites (Latinis and Dega 2009).

\section{EARTHWORK-SITE ECOLOGY AND LANDSCAPE INTERPRETATIONS}

Site morphology and distribution, lithic toolkits, pottery, and rice grain or chaff vacuoles in the pottery suggest that earthwork inhabitants were sedentary agriculturalists and horticulturalists, presumably practicing animal husbandry and keeping house gardens, the latter possibly placed within the settlements. Inhabitants most likely 


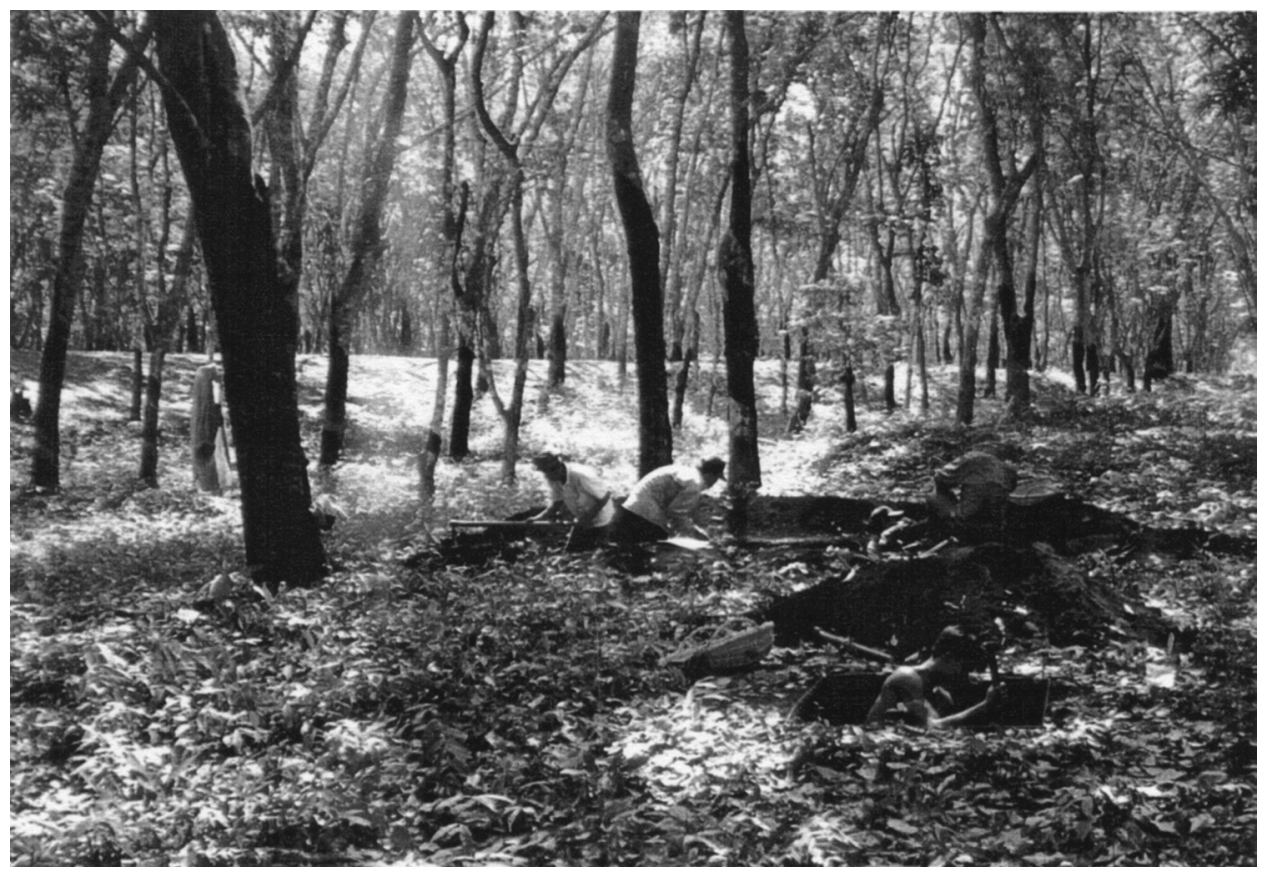

Fig. 4. Photograph of Chi Peang circular earthwork during excavation.

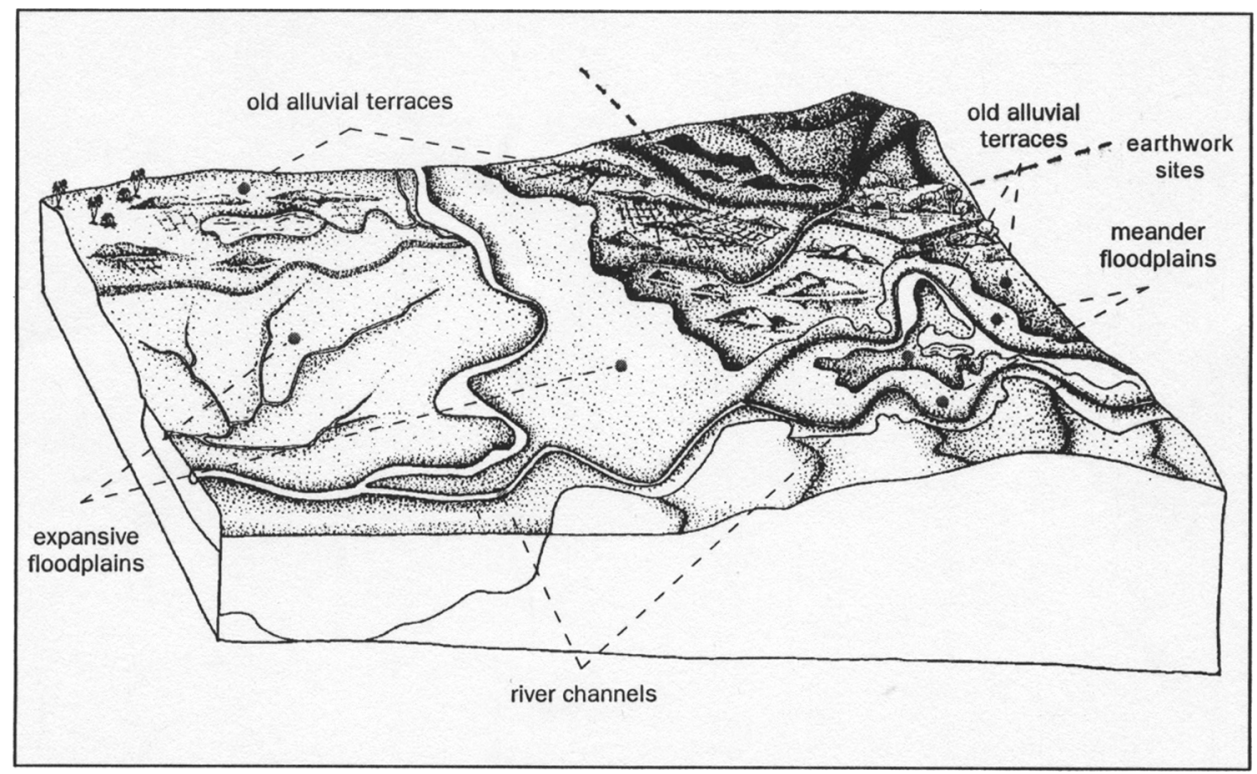

Fig. 5. Schematic geomorphological cross section of landscape showing general location of circular earthworks (adapted from M. R. Waters, 1996). 
manipulated forest plots, chamkar, and cleared fields/swidden exterior to the walls of the sites. ${ }^{3}$ Rice may also have developed through incipient wet and flood recession cultivation or by rain-fed means during the monsoonal wet season.

Assuming that dryland/hill swidden-like rice production was one of the central components in the food production economy, areas would have required some form of vegetation clearance and preparation. This would have created specific microecologies that differed from the surrounding forests. Rice may have dominated the target cultivated species. Also included in the spectrum of exploited and cultivated food products would have been root crops, garden crops, and tree crops, not unlike those characteristically grown by ethnographically documented hill-rice farmers native to mainland tropical Asia. The initial repertoire of species c. 2500 B.c. would not have included exotic species translocated from geographically separated areas (i.e., Wallacea and Sahul or the New World) such as the invasives and translocations characterizing the last 2000 years (e.g., corn, tomatoes, potatoes). The translocation histories, however, are not well known, with increased ambiguity prior to the colonial period and among Old World plants (as opposed to more readily identifiable New World introductions). The point is that a native species spectra existed, especially prior to Austronesian migrations and later colonial period introductions. This makes direct ethnographic comparison of species profiles tenuous. Palaeobotanical efforts are increasingly of methodological value and should weigh heavily when also assessing ethnographic comparisons.

Rice, some domesticated animals, and some plant species could have been introduced from elsewhere in mainland Asia much earlier, however. It is reasonable to speculate that certain species may have been initially introduced with Austronesian migration to the area c. 3000 years ago. Austronesians have a well-documented record of plant and animal translocations, and were in neighboring central Viet Nam by at least 1000-500 B.C., assuming Sa Hyunh material culture represents Austronesian groups. Almost all Neotropic species were introduced during the colonial and modern periods.

The species-genera ratios of banteay kou ecologies likely pulsed or cycled as fields were left fallow and then reworked. Depending on the investment required to defend and weed crops and produce, biodiversity likely increased in and around (peripheral) plots and gardens, particularly if the plots and gardens attracted non-human consumers. Clearance in general allows somewhat normative gap-succession dynamics to occur and frequently involves an initial increase in biodiversity from the time of clearance, although biodiversity decreases as plots develop through secondary stages and return to more mature/primary phases. Cultivated plots that promote food growth consumable by other animals would also be an attracting mechanism and increase local animal biodiversity.

Earthwork pottery and stone tools indicate a relationship with certain abiotic resources (specific clays and rock). However, it is unlikely that either clay or rock were exploited in such vast quantities that significant medium- to large-scale ecological impacts occurred. The presence of much localized pottery, however, indicates significant wood fuel extraction and use, both in making pots and food preparation. Pottery manufacture is likely to have had a cumulative effect on changing ecologies at local and intermediate scales. At the macroecology scale, however, it appears there was little long-term impact, if any at all. Given fairly low population density, a generic forest ecology seems to have been maintained throughout the region and never degraded. 
Forests certainly had reestablished themselves by early historic times, but it is probably more appropriate to say there was no need for recovery.

The abundance of axes, adzes, picks, and such in the diverse toolkit suggests heavy woodworking, wood processing, and small to medium plant/tree clearing. Thus, we presume the earthwork inhabitants exploited wood resources and targeted various disturbed and maturing forests. Fields and gardens needed to be cleared, and wood procured for building material, fuel, and other necessities. In some parts of the world, this practice may have had a significant cumulative effect, especially with increased animal husbandry contributions by grazing herd animals. ${ }^{4}$ However, there is no evidence for any serious lasting degradation or alteration of the terra rouge region. ${ }^{5}$ The only possible negative impact, or serious degradation or alteration, would have occurred at village and intermediate scales. However, the intermediate scale was undoubtedly well managed, or at least not degraded to the point of nonrecovery. Earthwork inhabitants were most likely in tune with long-term ecological processes and both shortand long-term maturation rates of biological resources. The long duration and sedentary nature of individual sites indicates that the adaptation was sustainable.

The overall earthwork picture contrasts sharply with later floodplain groups. Floodplain groups seriously modified the environment by incorporating: 1) increasingly more rice field area for flood recession and later irrigated rice agriculture, presumably at the expense of forests, marshes, and swamps; 2) infrastructural developments such as canals and roads; 3 ) overall water-systems alterations, and consequential aquatic community changes; 4) different species-genera ratios with distinctively different spatial patterns, many of which were managed (e.g., agricultural fields, house gardens, arboriculture plots); and 5) increasingly larger villages and eventually urban centers.

\section{Earthwork Ecology and Landscape Paradigm}

We now define the basic ecology model of earthwork settlement. We have found an evolutionary and economic approach to be quite useful. Simply put, individuals, as members of social groups, evolved to maximize fitness. Reproductive success is most associated with fitness, although energy acquisition is a primary concern (and is often used as a proxy variable). Individuals need energy and necessary nutrients in order to survive long enough to reproduce, physically or socially.

We view social group formation (i.e., the Mimotian earthwork grouping) as maximizing average fitness for the individuals in the group (economy of scale). At a certain level, population size reaches a point of diminishing returns. This depends to a significant degree on the type of economy, which is partially dictated by the environment as well as social factors such as technology and management success. These combined variables are undoubtedly an important factor concerning one essential feature of the circular earthwork sites: their relatively consistent size, with 4 to 6 ha representing the approximate range from minimum to maximum settlement size. Assuming this includes individual households, house gardens, possible animal pens, and communal spaces, but not agricultural fields, a rough but conservative estimate of 4 to 6 families per hectare results in about 25 families. A conservative estimate of 5 people per household results in an average banteay kou population of 125. More realistically, each banteay kou probably contained minimally one hundred to several hundred people, but did not exceed the upper hundreds to a thousand or more residents. 
As mentioned, the economy is largely dictated by environment, technology, information, problem-solving skills, and ecology. These are prime factors that set the limits of possibilities: what, potentially, can be productively exploited and how. However, the environment does not necessarily determine the economy. Humans intentionally and unintentionally manipulate the environment to adjust it to their desired economy. Just as invasive plant and animal species have no intention (as far as we know) of altering ecologies, but certainly do make changes ranging from nearly imperceptible to massive scales, with effects ranging from beneficial to devastating, humans also may not intend to alter their ecologies or realize they are producing change. Even by merely existing passively in an ecosystem, humans can and do change the ecologies they inhabit. In many cases, these changes are dramatic and highly visible.

The circular earthwork population probably intentionally manipulated the environment and the local ecology by managing it through such practices as clearance, house garden development, wall construction, and the development of agricultural plots. They were likely unaware that they were altering ratios of genotypes and species, however. They were also altering ecological relationships beyond merely introducing and cultivating plants they wanted, clearing areas for habitation and horticulture or agriculture, and keeping domesticated animals.

Because radiocarbon dates suggest that circular earthwork sites in eastern Cambodia and neighboring Viet Nam were constructed and used for a period of over 2000 years without any significant functional changes to the material culture, site morphology, or the generic environmental type and landscape, the banteay kou population seems to have been successful. The community maintained a consistent settlement pattern and total resource exploitation strategy embedded within a relatively consistent ecology for a few thousand years or more.

\section{The Earthwork Trajectory}

Development Phase - What led to the initial development of the Cambodian earthworks? Parsimony leads to an assumption that the shift to sedentism was associated with adaptations in agriculture and animal husbandry. This shift would have increased predictability and altered the economy by increasing energy returns and efficiency while decreasing expenditures and affecting settlement morphology and patterns. The ecology inherited from the inhabitants' predecessors would have been influenced by these changes. Even if the inhabitants migrated into an initially uninhabited zone, or invaded a sparsely inhabited zone, the ecology would have been altered.

The question of whether 1) agriculture and animal husbandry practices (the ideas, knowledge, technology) diffused into the area and what the rate of diffusion would have been; 2) agriculturalists (the people themselves) moved into the area; 3) agriculture evolved independently in the area; or 4) various combinations of these three processes occurred remains a subject of debate. Movement of practices and/or people practicing these economies into the area is more likely given that presumed plant and animal domesticates were not domesticated in the earthwork area (e.g., rice and domesticated animals were introduced from elsewhere). In this model, a "settlement ecology" would have moved in with the people and species. There is not a pattern, however, for the specific banteay kou circular earthwork phenomenon having moved into to the area from a separate region over time. Although circular settlement patterns 
are common throughout history around the planet, we cannot infer too much based on circular morphology alone.

It is reasonable to suggest that domesticated or semidomesticated plants and animals were moved into the area (more likelihood), and that the existing local inhabitants adopted new economies or parts of them, thereby transforming their existing economies (a piecemeal selected-aspect diffusion model). This is the more likely scenario given that the specific banteay kou settlement form is seemingly isolated. There is no evidence of a direct expansion history of this form of settlement from any of the usual suspects of domestication and sedentary settlement evolution "homelands" (e.g., it is doubtful that Chinese or Austronesian rice farmers systematically settled the area and replaced indigenous populations and subsistence economies). A more reasonable speculation is that animal husbandry and rice production were adopted into existing nomadic or semisedentary societies, which may have occurred initially in the east, thus explaining the east-west temporal shift between individual earthwork sites.

Social group size and relations are presumed to have changed before and after the earthwork phenomenon, but not during the period of earthwork construction and use, as indicated by site size consistency and morphological similarity throughout occupation duration. This does not imply that increasing group sizes or relations led to the development of banteay kou settlements in a causative manner. It is difficult to imagine population pressure as the stimulus for earthwork formation, or their subsequent abandonment, as a regional phenomenon. Data for estimating preexisting group size or indications of social complexity are simply absent. Based on the relatively few site assemblages dating to before 2500 B.C., it is presumed that most human groups in the area were relatively small forager communities, especially those in the hills and mountains. Group population sizes for circular earthwork groups can be more accurately estimated (at above the low hundreds) than can population sizes of the smaller foraging or hunter-gatherer groups that are assumed to have preceded them (generally estimated at much less than one hundred). Suggesting that the circular earthwork inhabitants formed social groups larger than that of their predecessors does not constitute a great leap of faith and indeed we make that assumption.

The longevity of banteay kou use precludes any notion of rapid ecosystem destruction leading to an obvious landscape footprint, such as changing forest into desert or grassland. We are only left with the settlement remains of walls and platforms and the stone tools and pottery contained within them. While the ecologies changed from before initial occupation to after abandonment, they probably remained fairly consistent and stable through the 2000-3000 years or more of general occupation and use, with little impact on the landscape (except for the earthen-walled rings) and no major ecological transformations. The regional or subregional ecosystem was probably typical of a relatively mature and minimally disturbed precolonial Mainland Southeast Asian forest area, interspersed with small human settlements, house gardens, agricultural or swidden plots, and varying degrees of disturbed forest.

In all, there are at least three scenarios for initial construction and subsequent occupation of the earthworks: invasive/immigrant, local evolution, or diffusion of some outside group's elements (domesticated animal husbandry and dry/swidden rice). The third scenario seems most probable. At this juncture, it is very difficult to imagine that rice and animal domesticates emerged independently from this earthwork settlement series. 
Occupation and Sustainability Phase - Two thousand years or more of earthwork occupation and group consistency and continuity seem to indicate a relatively decent balance and fairly successful management of sustainable ecological relationships, for the human component in particular. Given the available total exploitable resource environment, there is no reason to believe that the decline or abandonment of banteay kou sites around 500-300 B.C. was driven by ecological degradation processes. There is no evidence of self-induced environmental resource degradation through overexploitation, nor of massive global, semiglobal, or regional environmental changes (the likes of which are now hypothesized to be responsible for the decline of Angkor) at these earthwork sites (Buckley et al. 2010).

Given the known variables in the discussion above about earthwork ecology, there is little reason to believe that earthwork occupation could not have continued to present times. Sustained settlement occurred through proper care of the culture and the environment. The homogeneity of the sites through time, which indicates a successful adaptive strategy, has been documented archaeologically (Dega 2002).

Site Abandonment Phase - What led to the eventual abandonment of the circular earthworks? Did the sites slowly evolve into something different or did earthwork building and occupation simply cease? It does not appear that the banteay kou population had exhausted their resources or suffered a catastrophic natural disaster, or, were invaded, enslaved, coerced to change and move, etc.

Outside forces unrelated to environmental degradation or catastrophe more likely influenced abandonment of the sites. Increased commerce, new settlement strategies, and new opportunities to increase social and/or physical fitness may have pulled inhabitants toward the floodplains. A commercial, economic, and social pulling/ integrating force is more likely.

However, other factors should be considered. For example, some scholars theorize that general health declines as societies shift to sedentary agriculture. Siân Halcrow (2010: 7) states that, "today, over 850 million people, predominantly women and children, experience the plight of hunger, disease and poor living conditions, which had their ultimate beginnings with the development of agriculture and sedentism."

It is unlikely that earthwork inhabitants were aware of potential health trade-offs of moving to the floodplains, however. Site abandonment and rapid floodplain settlement may simply have become the preferred settlement strategy during the time of large-scale agriculture and long-distance trade.

As stated, it is more reasonable to postulate that better opportunities became available in the floodplains. That is, a more overall (including socioeconomic) fitnessenhancing, exploitable option became possible elsewhere. Given the 1) synchronous massive settlement of the floodplains; 2) appearance of large-scale long-distance trade and exchange networks (notably represented by artifacts such as bronze drums, glass beads, and metal-bronze and iron); 3) systematic restructuring of the floodplain ecology; 4) incipient urbanization; and 5) infrastructural developments such as canal building among other possible factors, it seems likely that the earthwork population moved toward increased opportunities to expand individual and/or group fitness and opportunities. These five factors may not have necessarily caused a decline in earthwork occupation directly, but may have indirectly led the population to more willingly alter their constant individual or group fitness practices for a more robust potential. 
The economic and social environment that emerged on the floodplains likely led to recruitment of many preexisting banteay kou people. By "recruitment," we mean that opportunities for banteay kou peoples in the floodplains would have been a significant enough attraction that they actively engaged with floodplain groups. While banteay kou people would still have been able to access and retrieve desired forest resources, they increasingly had the occasion to enter into the larger interaction sphere offered by floodplain settlement groups. Some groups may have chosen rejection, movement away, and continued isolation. Some groups may have chosen absorption. Other groups may have chosen semiautonomous and complementary connections. Some groups may have had no choice at all vis-à-vis any of these combinations. There is simply not enough available evidence to fully test all models.

Archaeologically, the abruptness of both circular earthwork site occupation and floodplain settlement eruption c. 300 B.C. suggests either rapid internal evolutionary change (including expansion onto the floodplains) or pressure from external groups, outcompeting or otherwise pressuring the earthwork inhabitants to assimilate. There is no evidence in the archaeological record of invasion by conquerors that either occupied the earthworks or caused their use as settlements to cease. It would be difficult to digest that the earthwork inhabitants were all exterminated by invaders. It is more likely that they were targeted (marginally if not significantly) for recruitment into the developing trade and production networks. The earthwork people would have had access to the forests, and presumably the knowledge of how to find and extract, or even produce, desired commodities from the forests. These commodities were valued and sought after by floodplain groups, since they represented the currency needed to obtain other exotic goods.

The time period marking terminal earthwork occupation and incipient floodplain occupation may synch with a subsistence economy and ecological shift in which the Tonle Sap Lake and river system ecologies became a major factor as well. Fishing and aquatic resources have often been overshadowed by the scholarly emphasis on rice production in describing ancient Khmer economies, but rice farmers were engaged as much in animal husbandry, house gardening, palm (i.e., Borassus) economies, quasi plantations, and manipulating forests (chamkar) as they were in rice cultivation. ${ }^{6}$

Early floodplain settlements were located on natural or anthropogenic mounded areas, at slightly higher elevations than the surrounding plains. Settlement sizes became significantly larger during this period. The sites are frequently characterized by vast amounts of pottery and burials. We do not yet have a good estimate of the average settlement size of the numerous early floodplain settlements, but a few estimates of contemporary settlements in Northeast Thailand at the terminal end of circular earthwork occupation (Ban Chiang Hian, Non Chai, Noen U-Loke) range in size from 18-50 ha (Higham 2002). Several sites in and around Thmar Puok in Banteay Meanchey (Northwest Cambodia) are estimated to range between 5 and 50 ha, while the Kamplong site in Kandal, just east of the Mekong, is estimated at 40-60 ha in size. The more urban sites of the Funan era, such as Angkor Borei, measure over 300 ha, indicating at least a sixty-fold increase in settlement size a short time after terminal earthwork occupation. Most early sites, however, are overlain with Funan to Angkor and post-Angkor settlement and possible modifications, as indicated by pottery and occasional architectural remains. This complicates initial settlement size estimation. Settlement size and morphology differentials, however, vis-à-vis subsistence and production ecologies, warrant additional considerations. 
The radial nature of the banteay kou sites, along with their comparatively small size and limited distribution across the landscape, suggests population pressure was not a factor in site abandonment. This implies that there was plenty of nonutilized, totalresource environmental potential available, so inhabitants could simply move if things became too crowded or overworked. The question remains whether or not the earthwork population was attracted to the different economy and ecology of the emerging, larger, commercially expansive, and well-connected floodplain areas. Did banteay kou inhabitants participate in the floodplain settlement process at all, or did they continue to live in the terra rouge region but ceased earthwork construction for some reason?

Earthwork inhabitants may have become part of the larger phenomenon of floodplain settlement, rather than remaining separate from it. That is, they may have become specialized producers of certain goods that fed into the regional, highly specialized, larger economic sphere. It is possible that specialists such as potters, tool makers, hunters, exotic good collectors, and so on existed among banteay kou communities. On the other hand, it seems quite likely that specialist communities, rather than households in a community, may have developed in the floodplains as well. That is, entire villages or village clusters probably became potting centers or iron-working areas such as exist to the present day. They would have fed into a larger socioeconomic and political entity, such as a kingdom.

The banteay kou people may have been absorbed into such a polity by supplying specific resources from their total resource environment. They probably extracted such forest resources as beeswax, resins, aromatic woods, and forest animals, along with rare animals or specific rare animal parts, and perhaps commodities such as hardwoods to use for lumber as these products were in demand from the Funan to the Angkorian and even European colonial periods. The EDXRF data suggest that earthwork pottery was not one of the possible commodities, however (Latinis and Dega 2009). Ubiquitous locally and cost-effectively produced commodities were not, nor would they be expected to be, in major trade circulation. This pattern would appear only if more cost-effective production and distribution industries were created and demand remained (as seen with later pottery industries, e.g., Funan, pre-Angkor, Angkor, post-Angkor, etc.).

These factors may have significantly altered the earthwork economy by increasing the focus on exotic good acquisition in exchange for highly demanded and rare resources from hill-region/mountain forests. For the banteay kou people, this may have also resulted in decreased attention to growing rice, which could be acquired through trade. These features could have led to altering the traditional settlement patterns of living in village-sized, walled settlements, limited the duration of settlement at certain locations, and changed the nature of subsistence acquisition. Such cumulative changes would have altered their ecologies as well, although a generic tropical forest ecology was maintained throughout the terra rouge region.

Given this discussion, it is feasible to suggest that much of the banteay kou population may have been recruited to the floodplains, while some stayed in the terra rouge region to specialize in exotic resource extraction from the forests and a few others continued with their preexisting normative lifestyle in the area, but stopped constructing walled settlements. In short, the terminal period was likely one of divisiveness for the earthwork population.

In the ecological model proposed herein, transition was facilitated by an increase in the fitness of the population through agricultural and fishing intensification (for 
floodplain settlements), long-distance trade, and increased exploitation and acquisition of highly valued local resources. ${ }^{7}$ In this scheme, earthwork populations also acquired resources through increased specialization in resource production and extraction, and through subsequent exchange. Exchange thus increased overall efficiency for the entire interacting population. Agricultural and fishing commodities, as well as exotic forest products, were possibly used as part of the exchange currency for extralocal exotic goods or materials. Assuming that many of the former terra rouge populations migrated to the floodplains during this period, it is unlikely that population pressure was a "push" factor; rather, the new economy and trade network was undoubtedly the driver, that is, an attraction or "pull" factor.

To sum up, terminal earthwork site occupation c. 500-0 B.c. is presumed to represent a protohistoric transitional period for development in Cambodia. Earthwork populations expanded onto the plains or were incorporated into the floodplain settlements that began developing rapidly around 500 B.C. Floodplain expansion occurred at approximately the same time that banteay kou occupation and use dissipated, which is not likely coincidental. Earthwork sites may have become absorbed into or even partly helped initiate a much larger social and economic system that was increasingly based on floodplain wet-rice agriculture, fishing, and trade, among other social and economic factors.

\section{Site Abandonment Model}

The following "ecological" model provides three potential scenarios for circular earthwork abandonment (Fig. 6). Three "time periods" are proposed as interaction spheres, with each "time period" reflecting population locations. These three do not reflect a definitive universe of possibilities and, to date, none of the three can be shown to be the best "fit"; there are elements of each that may be true and/or also negated. The model incorporates demographic, settlement, social complexity, technological, and economic data, with significant attention to the overall ecologies. The temporal period is from c. 700-200 B.c. and slightly after.

Time Period 1 - Circular earthwork populations thrived in small groupings across the terra rouge region, with very few inhabitants in the floodplains. The floodplains may have constituted part of the total resource environment, however, particularly later in banteay kou timelines as populations moved closer to the plains. There was likely some form of interaction (e.g., marital exchanges, raids) between contemporaneous banteay kou settlements as evidenced by the high redundancy of material culture and site morphology. Since there are no differences in pottery or tool styles, competition between settlements or the need to demarcate separate identities does not appear to have existed.

Time Period 2 - This scenario provides for some interaction between earthwork populations and small floodplain groups. Interaction among banteay kou sites likely continued. Village specialization within each other's econiches may have occurred to some degree, but was self-contained for the most part within the larger interactive spheres representing separated floodplain populations and banteay kou populations (Fig. 6). The floodplain groups would likely have interacted more amongst themselves than with the banteay kou groups. The same can be speculated for the banteay kou groups. 
Time Period 1: Inter-settlement distances are unlikely to be geographically equal. However, more even dispersement may occur depending upon critical resource distribution, total resource environment, and carrying capacity. Smaller settlements may require less resource environment space. Physical and social carrying capacity possibly results in fissioning of settlements over time. Inter-settlement interaction spheres (i.e., social, trade, conflict) are unknown based on material culture analysis proxies, but a common cultural identity is evident from consistency.

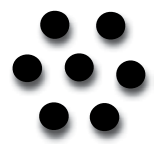

Time Period 2: Specialist (e.g., pottery manufacture) settlements may occur. Interaction spheres more evident (e.g., pottery production and distribution analyses may identify and define interaction spheres). Some settlements may remain more detached or isolated. Outside exchange and influence may occur at some point in time (e.g., Bronze and Iron Ages). Settlement nature, size, function, and social interactions may change organically (internally) or may be stimulated by outside factors (e.g., trade, exchange, migration, diffusion, etc.).

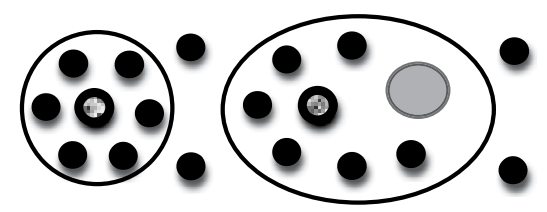

Time Period 3: Larger interaction spheres develop as settlement types and sizes evolve. Some interaction spheres may serve larger interaction spheres as "specialist" phenomena (e.g., forest product extractors). Long-distance trade or exchange for specialized and exotic goods becomes more prominent (e.g., Funan Period, Angkor Borei). Few traditional settlements remain and some are more isolated than others. Some remote settlements may have developed specialist exotic good industries and maintained connections to larger interaction sphere.
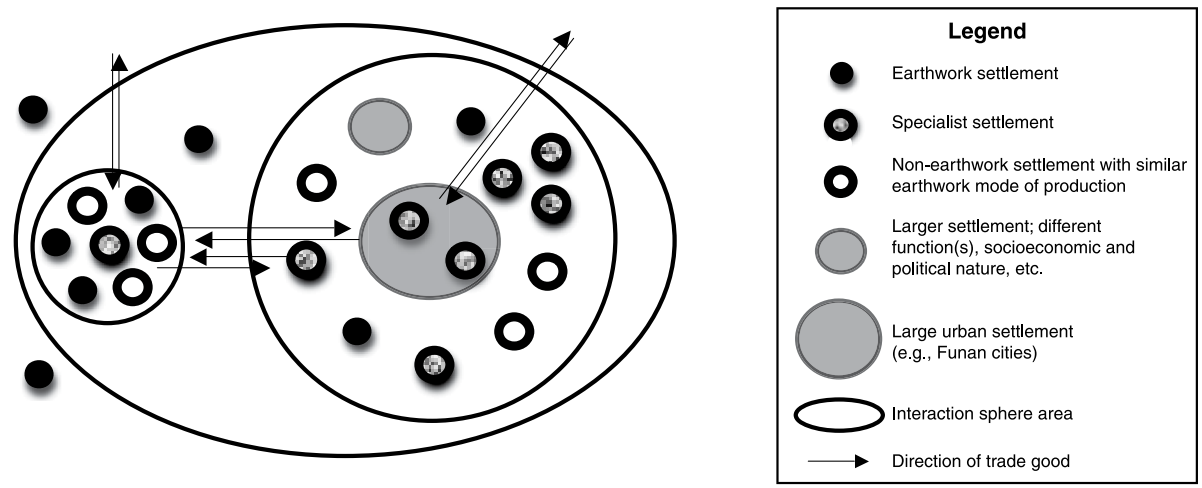

Fig. 6. Hypothetical schematic depicting earthwork interaction sphere through time.

Time Period 3 - This scenario models large-scale exotic trade, movement, or recruitment of a significant number of the earthwork population to the plains, with some earthwork people remaining in the forest to specialize in acquiring forest products, while others continue their subsistence activities, but cease maintenance of walled settlements. By 300 B.C., building new walls had completely ceased in terra rouge and the population was no longer living in the walled settlements. The earthwork populations and floodplain populations interacted, many specialized villages and larger 
settlements in the floodplains developed, and centralized preurban to incipient urban sites subsequently occurred in the floodplains, during the Funan period.

Overall, we support the notion that the floodplain populations did not originate in the hills. That is, the banteay kou inhabitants were part of a large cast in the floodplain drama, but not its instigators or principal characters. Assuming that the earthwork population was meeting or exceeding nutrient and caloric fitness requirements (i.e., more than enough food to survive), why, in ecological and evolutionary terms, did the demand for exotics arise? This may be addressed in terms of reproductive fitness enhancement, as discussed above, or as survival and security enhancement factors (social, economic, biological, and other factors considered independently, combined, and so forth-fuel for further speculation and model testing).

\section{CONCLUSIONS AND FUTURE RESEARCH}

Very few historical ecology studies have been conducted in the immediate region of the prehistoric circular earthworks. This lack is symptomatic of Southeast Asian research in general, although Bettinger (1991) notes that systemic ecological models began challenging other developmental models as early as the 1960s and 1970s in anthropological studies of hunter-gatherers. While the influence of Julian Steward's early ecological approach on both anthropology and archaeology should not be ignored, historical ecology as a separate field is still in its infancy in Southeast Asia. This is particularly true in relation to Cambodian archaeological research that focused on temporal periods predating the Angkorian civilization, when large-scale landscape modifications become obvious. Most Angkorian studies have focused on art and architectural history, with a few early exceptions such as Groslier's (1979) hydraulic city theory. Other earlier approaches concerning prehistoric populations have focused on how humans adapted to or targeted existing ecologies and what impacts those environments had on them (Gorman 1971). When and where domesticated rice occurred has been a discussion point, but the discussion has not been embedded within a more realistic corpus of subsistence resource change and changes in species-genera ratios over time. Nonetheless, data and models from past studies on environmental reconstruction, diet, health, and subsistence can be applied within a historical ecology framework. More recently, archaeologists have begun exploring how humans have intentionally or unintentionally modified or maintained ecologies, or become interlaced within their ecologies, with ensuing changes at various scales.

A primary goal of this article has been to use an ecological perspective to understand prehistoric Cambodian earthworks. We have attempted to move the discussion beyond normal archaeological and ecological discourses. We then interpreted the earthwork trajectory from initial site formation through continued use and finally site decline or abandonment. Our causative model for site abandonment demonstrates that marrying historical ecology to archaeology broadens understanding of changes in these and other archaeological sites through time and space.

The development of agricultural economies is certainly significant in relation to the ecologies of the terra rouge hill or mountain region of eastern Cambodia and neighboring Viet Nam. Using various scales of analysis, the circular earthwork site (banteay kou) inhabitants are our central point of departure for understanding complex ecological webs across space and time. The inhabitants were farming rice, presumably as part of a dry hill rice economy more akin to swidden than the wet-rice farming 
characteristic of flood recession or irrigated economies that later developed in the floodplains. Although there are Holocene macroenvironmental considerations that warrant attention in relation to human settlement and subsistence economies, the transition from foraging to early rice agriculture and assumed horticulture and animal husbandry in the terra rouge region is almost completely unknown. With the data at hand, we can only see that the banteay kou suddenly appeared around 2500 B.C. and remained consistent for about two thousand years thereafter.

While they may have added a wet-rice component at some point, it would have likely emerged toward the twilight of banteay kou settlement history. Had it occurred at all, current data would indicate it would have likely been seasonal, following monsoon weather, wet/dry patterns, and parallel tributary river flooding and recession in areas that fanned out toward the greater floodplains. There are no apparently related landscape modifications or feature constructions to indicate support for wet-rice contributions during the earthwork occupation period, however. Additionally, there is no pollen, macrobotanical, or faunal data that would suggest the inhabitants utilized an incipient wet-rice subsistence economy, or targeted ecosystems and environments common to wet-rice economies. There are also no recorded fish, or material culture remains related specifically to fish or other water resource exploitation, that would suggest the earthworks inhabitants targeted resources from lakes, rivers, wetlands, and wet-rice environments, although, in tandem with rice agriculture, exploiting water resources is one of the key components of later floodplain economies.

The terminal period of circular earthwork settlement coincided with punctuated floodplain settlement around 500-300 B.C. By this time, wetland, lake, and riverine ecologies were central to rice production and fishing economies. While the seeds of the floodplains' economies may have been sown during the upland Neolithic period, there are no indications that the exploitation, modification, or creation of this type of ecosystem developed during the time the earthworks were occupied, at least not on the scale that defines the metal ages of the early Funan to Funan, pre-Angkor, Angkor, and post-Angkor settlements of the floodplains.

We suggest that individual banteay kou sites were permanently occupied in at least 400-700-year time frames, which implies considerable overlap in earthwork site occupation. We discussed the tendency of the older sites occuring in the eastern portion of the plateau; they were thus further removed from the floodplain in adaptive terms than the younger western sites. This trend supports the idea that hill and mountain people progressively moved toward the floodplains and lowlands over time after around 3000 B.C. ${ }^{8}$ The fact that this is approaching the time when the mid-Holocene high sea levels began receding is significant as well, especially for lower Mekong floodplain settlement, and is certainly an important consideration for historical ecology. The delta, floodplains, and perhaps the Tonle Sap Lake region would likely have been affected by saline tidal waters prior to that (Penny 2006) and possibly until Sathiamurthy and Voris' (2006) calculated maxima, around 2200 B.C., with an estimated rise of five meters above current sea level (Sathiamurthy and Voris 2006). Presumably, it took centuries, if not millennia, to recede to the current levels. The floodplains may have offered very different resources to the initial banteay kou settlers in c. 2500 B.C. than to their descendants at around 500 B.C.

In addition, radiocarbon dates show that, with the exception of a few sites such as the Koh Ta Meas burial grounds in West Baray, Angkor, the floodplain settlements in the south were generally earlier than in the north (Reineke et al. 2009). Current data 
are still too limited to allow us to assign a southern origin of floodplain settlement during the metal ages, however, so this is a topic for future research.

The earthwork terminal period is particularly interesting because there was either: 1) a rapid economic, ecological, settlement, material culture, and long-distance exotic commerce evolution or introduction involving the banteay kou people; or 2) the same, but excluding the banteay kou people; or 3) the same, through a process of diffusion; or 4) the same, but by immigrant populations. It is difficult to determine which scenario is a "best fit" in light of our present data, or to know if several of these combined processes were involved. We argue that the banteay kou descendents were recruited into the early floodplain economies and ecologies, with some earthwork peoples remaining to eventually specialize in extraction of forest resources for extralocal exchange.

What is known is that the landscape footprint of the banteay kou people stopped being imprinted at about the same time as floodplain settlement appeared, a situation that is not likely coincidental. The imprint left by the early floodplain settlers on landscape, biology, and ecologies is exceptionally different (not necessarily destructive but certainly transformative), with the emergence of canals, infrastructure, larger settlements, and urban sites, as well as food and other commodity production industries. Conterminously, the imprint of early floodplain settlers significantly altered the preexisting biotic species-genera distributions. Other than the earthwork walls and platform housing, scattered remains of pottery, and stone tools, the banteay kou footprint is virtually invisible. Ecologies, environments, and landscapes would have been altered at the local scale, but the macroscale seems to have remained comparatively undisturbed. This visible contrast vis-à-vis transformation of the environment, ecology, and landscape warrants further questioning about the relative connectedness or isolation of banteay kou occupants and floodplain people at that critical period in time.

This article has sought to build upon a normative archaeological foundation to address complex questions about earthwork settlement, from incipient times through abandonment of the sites. Historical ecology variables are assessed for the sites and a model presenting scenarios for earthwork terminal occupation. Beyond the earthwork study itself, questions about early floodplain settlement in Cambodia are briefly addressed. We offer a vehicle to larger archaeological and historical ecology questions that may be more widely applicable, such as: Do migrating people initially select environments mimicking the ones they departed? We suggest that migrating peoples initially target similar environments or resource bases, then diversify through time. Such was likely the case during the Pleistocene, Austronesian expansion, and beyond. Similar ideas noted within this article should allow us to continue assessing archaeological and ecological data sets in tandem; the fruits of such comparisons will generate a better understanding of history.

\section{NOTES}

1. Note that, at present, there appears to be no significant relation to other circular sites such as those often discussed in Thailand (see Moore 1988).

2. There are supposedly 55 known earthwork sites at this writing, although morphological and location data are marginal (T. Chanthourn, pers. comm., 2010).

3. Chamkar are forest plots or distant mixed gardens, agricultural plots, and trees. They are not house gardens, which are found proximate to residences. 
4. The Indonesian government today frequently blames slash and burn agriculturalists for forest degradation, which is likely untrue. Clearance for agricultural expansion, however, certainly does reduce forest area.

5. Terra rouge is a common descriptive term for the hill region because of its characteristic red earth, resulting from the iron rich volcanically derived soils.

6. All subsequent kingdoms revolved around the Tonle Sap, including Funan to the south, followed by Chenla to the east, Angkor to the north, and finally Udong and Lovek to the southwest by the early colonial period, with a return to the south (Phnom Penh) in more recent historic and modern times.

7. Particularly the exotic forest resources that continued to be highly demanded throughout almost two thousand years of historic records (see Maxwell 1999 for example).

8. Glover and Bellwood (2004) describe the expansion from hills into river valleys, floodplains, and coastal areas in northern Viet Nam.

\section{REFERENCES CITED}

Albrecht, B.

1999 Pollen samples from Krek 62/52. Paper presented at Conference on Circular Earthworks in Cambodia, 14 to 19 November. Faculty of Archaeology, Royal University of Fine Arts, Phnom Penh, Cambodia.

Albrecht, G., M. Haidle, S. Chhor, L. H. Heang, S. Heng, T. Heng, S. Mao, K. Sirik, S. Som, C. Thuy, AND L. VIN

1999 Recent Studies of Circular Earthworks. Phnom Penh: Royal University of Fine Arts.

BetTinger, R. L.

1991 Hunter-Gatherers: Archaeological and Evolutionary Theory. Interdisciplinary Contributions to Archaeology. New York: Plenum Press.

Buckley, B. M., K. J. Anchumaitis, D. Penny, R. Fletcher, E. R. Cook, M. Sano, L. C. Nam, A. Wichienkeeo, T. T. Minh, And T. M. Hong

2010 Climate as a Contributing Factor in the Demise of Angkor, Cambodia. Online Proceedings of the National Academy of Sciences of the United States of America. www.pnas.org/ content/107/15/6748.full.

DEGA, M. F.

1999 Circular settlements within eastern Cambodia. Bulletin of the Indo-Pacific Prehistory Association 18:181-190.

2002 Prehistoric Circular Earthworks of Cambodia. BAR International Series 1041. Oxford: Archaeopress.

Dega, M. F., K. Vet., C. Chamroeun, and K. Samen

1997 Circular earthworks in Kampong Cham: 1996 Archaeological research. Bulletin de l'École française d'Extrême-Orient $84: 13-16$. Phnom Penh, Cambodia (in English and Khmer).

Glover, I., AND P. BellwoOd

2004 Southeast Asia: From Prehistory to History. London: RoutledgeCurzon.

Gorman, Chester

1971 The Hoabinhian and after: Subsistence patterns in Southeast Asia during the latest Pleistocene and early recent periods. World Archaeology $2: 300-320$.

Groslier, B. P.

1966 Indochina. London: Miller.

1979 La cité hydraulique angkorienne: Exploitation ou surexploitation du sol? Bulletin de l'École française d'Extrême-Orient 66:161-202.

HAIDLE, M. N.

2002 The fragment of a glass bracelet from Krek 52/62 and its implications for the dating of the Mimotien culture. Asian Perspectives 40(2): 195-208.

HALCROW, SIÂN

2010 New research in northeast Thailand. Bioarchaeology in Southeast Asia and the Pacific: Newsletter 6:6-7, ed. K. Domett. http://researchonline.jcu.edu.au/27062/1/Bioarchaeology_in_ Southeast_Asia_and_the_Pacific_Newsletter_2010_Issue_6.pdf.

Higham, C.F.W.

2002 Early Cultures of Mainland Southeast Asia. Bangkok: River Books. 
Kojo, Y., AND S. Pheng

1997 A newly discovered earthwork in southeastern Cambodia. Journal of Anthropological Science 105(3) : 181-187.

Latinis, D. K., AND M. F. Dega

2009 Possible production centers of Cambodian circular earthwork ceramics as explained through EDXRF analysis. Paper presented at the 2010 Indo-Pacific Prehistory Association Meetings, Hanoi.

Maxwell, A. L.

1999 Holocene Environmental Change in Mainland Southeast Asia: Pollen and Charcoal Records from Cambodia. Ph.D. diss. The Department of Geography and Anthropology, Louisiana State University and Agricultural and Mechanical College, Baton Rouge.

Moore, E.

1988 Moated Sites in Early North East Thailand. British Archaeological Records International Monographs Series 400. Oxford.

Nop, R., S. Oun, K. Loeun, P. Hoeung, and S. Nup

1996 An Archaeological Study of a Circular Earthwork at Krek, Southeastern Cambodia. Unpublished thesis. Faculty of Archaeology, Royal University of Fine Arts, Phnom Penh, Cambodia.

PENNY, DAN

2006 The Holocene history and development of the Tonle Sap, Cambodia. Quaternary Science Reviews $25(3 / 4): 310-322$.

Reineke, A., V. Laychour, and S. Sonetra

2009 The First Golden Age of Cambodia: Excavations at Prohear. Bonn: Thomas Muster.

Sathiamurthy, Eldic, and Harold K. Voris

2006 Maps of Holocene sea level transgression and submerged lakes on the Sunda Shelf. The Natural History Journal of Chulalongkorn University, Supplement 2:1-44.

SOPHADY, H.

n.d. General archaeological aspects and speculations concerning the red soil region east of the Mekong River in Kampong Cham Province, Cambodia. Unpublished report. Memot Centre for Archaeology. Phnom Penh, Cambodia.

WATERS, M. R.

1996 Principles of Geoarchaeology: A North American Perspective. Tucson: University of Arizona Press.

\begin{abstract}
This article moves discussion of prehistoric earthworks in Cambodia from normative archaeology into an ecological landscape structure, based on archaeological data sets. Discussions provide a synthesis of archaeological and newly borne-out ecological explanations for original site construction, occupation, landscape use, sustainability of occupation for the earthwork culture over a 2000-year period and terminal use of the sites. A model is presented to assess site abandonment and post-earthwork region settlement patterns. KEYwORDS: Cambodia, prehistoric circular earthworks, landscape archaeology, historical ecology, sustainability, site abandonment modeling.
\end{abstract}

